\title{
Enzastaurin inhibits ABCB1-mediated drug efflux independently of effects on protein kinase $C$ signalling and the cellular p53 status
}

\author{
Martin Michaelis ${ }^{1,2}$, Florian Rothweiler ${ }^{1}$, Nadine Löschmann ${ }^{1}$, Mohsen Sharifi ${ }^{3}$, \\ Taravat Ghafourian ${ }^{3}$, Jindrich Cinatl Jr.. \\ ${ }^{1}$ Institut für Medizinische Virologie, Klinikum der Goethe-Universität, Frankfurt am Main, Germany \\ ${ }^{2}$ Centre for Molecular Processing and School of Biosciences, University of Kent, Canterbury, UK \\ ${ }^{3}$ Medway School of Pharmacy, Universities of Kent and Greenwich, Chatham Maritime, Kent, UK \\ Correspondence to: \\ Jindrich Cinatl Jr., e-mail: Cinatl@em.uni-frankfurt.de \\ Keywords: ONC201, cancer drug, TIC10, NSC350625 \\ Abbreviations: ABC transporter, ATP-binding cassette transporter; MARCKS, myristoylated alanine-rich C-kinase substrate; \\ MTT, 3-(4,5-dimethylthiazol-2-yl)-2,5-diphenyltetrazolium bromide; RCCL collection, Resistant Cancer Cell Line collection \\ Received: September 09, $2014 \quad$ Accepted: December 09, $2014 \quad$ Published: February 13, 2015
}

\section{ABSTRACT}

The PKC $\beta$ inhibitor enzastaurin was tested in parental neuroblastoma and rhabdomyosarcoma cell lines, their vincristine-resistant sub-lines, primary neuroblastoma cells, ABCB1-transduced, ABCG2-transduced, and p53-depleted cells. Enzastaurin $\mathrm{IC}_{50} \mathrm{~s}$ ranged from 3.3 to $9.5 \mu \mathrm{M}$ in cell lines and primary cells independently of the ABCB1, ABCG2, or p53 status. Enzastaurin $0.3125 \mu$ M interfered with $A B C B 1-m e d i a t e d$ drug transport. PKCa and $P K C \beta$ may phosphorylate and activate $A B C B 1$ under the control of p53. However, enzastaurin exerted similar effects on ABCB1 in the presence or absence of functional p53. Also, enzastaurin inhibited PKC signalling only in concentrations $\geq 1.25 \mu \mathrm{M}$. The investigated cell lines did not express PKC $\beta$. PKCa depletion reduced PKC signalling but did not affect ABCB1 activity. Intracellular levels of the fluorescent ABCB1 substrate rhodamine 123 rapidly decreased after wash-out of extracellular enzastaurin, and enzastaurin induced $A B C B 1$ ATPase activity resembling the $A B C B 1$ substrate verapamil. Computational docking experiments detected a direct interaction of enzastaurin and $A B C B 1$. These data suggest that enzastaurin directly interferes with $A B C B 1$ function. Enzastaurin further inhibited ABCG2-mediated drug transport but by a different mechanism since it reduced ABCG2 ATPase activity. These findings are important for the further development of therapies combining enzastaurin with $A B C$ transporter substrates.

\section{INTRODUCTION}

Enzastaurin (also known as LY317615) was synthesised as protein kinase $\mathrm{C}(\mathrm{PKC}) \beta$ inhibitor based on the structure of staurosporine, a natural compound known to interfere with PKC signalling [1]. In pre-clinical models, enzastaurin displayed activity against cancer cells from different entities including carcinomas, glioblastoma, melanoma, and different haematological malignancies as well as anti-angiogenic effects [2-13]. The substance has been investigated for its effects against various cancer types in clinical trials [4, 13-22].

We had previously shown that enzastaurin activates glycogen synthase kinase (GSK) $3 \beta$ in natural killer cells and in turn reduces their activity [23]. To test the effects of (potential) anti-cancer agents in the context of cellular chemoresistance mechanisms, we have established the Resistant Cancer Cell Line (RCCL) collection, a collection of cell lines from 15 different cancer entities with acquired resistance to various 
cytotoxic and targeted anti-cancer drugs (http://www. kent.ac.uk/stms/cmp/RCCL/RCCLabout.html) including cell lines derived from the paediatric cancer entities neuroblastoma and rhabdomyosarcoma. Significant subgroups of patients suffering from these cancers are high-risk patients with very poor prognosis [24-27]. Vincristine is a constituent of therapy regimens for both neuroblastoma and rhabdomyosarcoma [24-28]. Here, we tested enzastaurin alone or in combination with vincristine in a panel of parental neuroblastoma and rhabdomyosarcoma cell lines and their vincristineresistant sub-lines.

\section{RESULTS}

\section{Influence of enzastaurin on viability of neuroblastoma and rhabdomyosarcoma cells}

Enzastaurin interfered with the viability of chemosensitive and chemoresistant neuroblastoma and rhabdomyosarcoma cells in similar concentrations, enzastaurin $\mathrm{IC}_{50}$ values ranged from 3.74 to $8.20 \mu \mathrm{M}$ (Table 1). Similar results were obtained in primary MYCN-amplified neuroblastoma cells (Table 2).

$\mathrm{ABCB} 1$ and $\mathrm{ABCG} 2$ are major ATP-binding cassette $(A B C)$ transporters that are involved in the passage of drugs, xenobiotics, and food constituents through cellular and tissue barriers and consequently in their absorption, distribution, and excretion. Moreover, $\mathrm{ABCB} 1$ and $\mathrm{ABCG} 2$ are frequently found highly expressed on cancer cells playing an important role in cancer cell chemoresistance [29-31]. p53 is a major tumour suppressor gene. Loss-of-p53 function has been associated with decreased drug sensitivity in cancers including neuroblastoma $[32,33]$. However, neither p53 functionality nor $\mathrm{ABCB} 1$ or $\mathrm{ABCG} 2$ expression status significantly modified enzastaurin sensitivity of the investigated cell lines (Table 1).

\section{Enzastaurin sensitises $\mathrm{ABCB} 1$-expressing cells to cytotoxic $A B C B 1$ substrates}

Next, the influence of enzastaurin was tested on the vincristine sensitivity of neuroblastoma and rhabdomyosarcoma cells. Enzastaurin $1.25 \mu \mathrm{M}$, a concentration that did not significantly affect cell line viability, sensitised $\mathrm{ABCB} 1$-expressing vincristineresistant cells to the ABCB1 substrate vincristine but did not substantially change the vincristine sensitivity of the respective parental cell lines that express low levels of ABCB1 (Figure 1A, Suppl. Table 1). Effects were similar in vincristine-adapted, $\mathrm{ABCB} 1$-expressing cells and in UKF-NB-3 ${ }^{\mathrm{ABCB} 1}$ cells transduced with a lentiviral vector encoding for $A B C B 1$ (Figure 1B, Suppl. Table 1).
$\mathrm{ABCB} 1$ recognises a broad range of structurally different substrates. In concordance, enzastaurin 0.625 $\mu \mathrm{M}$ and $1.25 \mu \mathrm{M}$ also dose-dependently sensitised ABCB1-expressing UKF-NB- $3^{\mathrm{r}} \mathrm{VCR}^{10}$ cells (that do not express $\mathrm{ABCC} 1, \mathrm{ABCC} 2, \mathrm{ABCC} 3, \mathrm{ABCC} 5$, or $\mathrm{ABCG} 2$, data not shown) to the alternative cytotoxic $\mathrm{ABCB} 1$ substrates paclitaxel and actinomycin D (Figure 1C, Suppl. Table 2). Enzastaurin further sensitised ABCB1expressing UKF-NB- $3^{r} V_{C R}{ }^{10}$, UKF-NB- $2^{r} V_{C R}{ }^{10}$, $\mathrm{KFR}^{\mathrm{r} V C R}{ }^{10}$, and $\mathrm{Rh} 30^{\mathrm{r}} \mathrm{VCR}^{10}$ cells (but not nonABCB1-expressing UKF-NB-3, UKF-NB-2, KFR, and Rh30 cells) to vincristine in a dose-dependent manner. Enzastaurin concentrations as low as $0.3125 \mu \mathrm{M}$ were found to enhance vincristine activity (Figure 1D, Suppl. Table 3A-3D).

Finally, we investigated the influence of enzastaurin on the efflux of the fluorescent $\mathrm{ABCB} 1$ substrate rhodamine 123 in $\mathrm{ABCB} 1$-expressing UKF-NB-3 ${ }^{\mathrm{r}} \mathrm{VCR}^{10}$ cells. Enzastaurin caused a concentration-dependent increase in rhodamine 123 fluorescence in the UKFNB-3 ${ }^{r} V R^{10}{ }^{10}$ cells (Figure 1E) but did not affect ABCB1 expression (data not shown).

\section{Direct interaction of enzastaurin with $\mathrm{ABCB} 1$}

Previous reports had indicated that $\mathrm{PKC} \alpha$ or $\mathrm{PKC} \beta$ may promote $\mathrm{ABCB} 1$ function by phosphorylation [34, 35]. Therefore, enzastaurin may affect $\mathrm{ABCB} 1$ function through direct interaction with $\mathrm{ABCB} 1$ and/or inhibition of PKC-mediated ABCB1 phosphorylation. Enzastaurin affected $\mathrm{ABCB} 1$ function in concentrations as low as $0.3125 \mu \mathrm{M}$ (Figure 1D, Figure 1E, Suppl. Table 3). Since enzastaurin was shown to inhibit PKC $\beta$ enzyme activity with an $\mathrm{IC}_{50}$ of $0.03 \mu \mathrm{M}$ and $\mathrm{PKC} \alpha$ activity with an $\mathrm{IC}_{50}$ of $0.8 \mu \mathrm{M}$ in isolated enzyme assays [1], enzastaurin-mediated effects on $\mathrm{PKC} \alpha$ signalling are unlikely to be responsible for the reduced $\mathrm{ABCB} 1$ activity. Myristoylated alanine-rich C-kinase substrate (MARCKS) is a PKC substrate, and MARCKS phosphorylation is a surrogate parameter for PKC activity [3, 4]. Enzastaurin inhibited MARCKS phosphorylation in UKF-NB-3 ${ }^{r} \mathrm{VCR}^{10}$ cells only in concentrations of $1.25 \mu \mathrm{M}$ or higher after $6 \mathrm{~h}$ of incubation. After $120 \mathrm{~h}$, only an enzastaurin concentration of $5 \mu \mathrm{M}$ reduced MARKS phosphorylation (Figure 2A). Since enzastaurin inhibits ABCB1 function in concentrations as low as $0.3125 \mu \mathrm{M}$ (Figure 1D, Suppl. Table 3), this finding suggests that the enzastaurinmediated inhibition of $\mathrm{ABCB} 1$ function may not be the consequence of inhibition of $\mathrm{PKC}$-mediated $\mathrm{ABCB} 1$ phosphorylation.

Next, we wanted to test whether interference with PKC signalling is sufficient to interfere with $\mathrm{ABCB} 1$ function in our model. Although we readily detected $\mathrm{PKC} \beta$ in K562 cells that had served as positive control, we were not able to detect PKC $\beta$ in UKF-NB- $3^{r} V{ }^{10}{ }^{10}$ cells 
Table 1: Influence of enzastaurin on neuroblastoma and rhabdomyosarcoma cell viability. Expressed as concentration that reduces cell viability (determined by MTT assay) after a 5 day incubation period by $50 \%\left(\mathrm{IC}_{50}\right)$

\begin{tabular}{|c|c|c|c|}
\hline Cell line & p53 status & ABCB1 & $\mathrm{IC}_{50}{ }^{(1)}$ enzastaurin $(\mu \mathrm{M})$ \\
\hline UKF-NB-3 & wild-type & $-(2)$ & $6.31 \pm 0.98^{(3)}$ \\
\hline UKF-NB-3r $^{r} \mathrm{VCR}^{10}$ & mut $(\mathrm{C} 135 \mathrm{~F})^{(4)}$ & + & $5.33 \pm 1.09$ \\
\hline UKF-NB-3 ${ }^{\mathrm{ABCB} 1(5)}$ & wild-type & + & $9.46 \pm 1.89$ \\
\hline UKF-NB-3 ${ }^{\mathrm{Cer2}(6)}$ & wild-type & - & $8.44 \pm 0.95$ \\
\hline UKF-NB-3 ${ }^{\mathrm{ABCG} 2(7)}$ & wild-type & - & $5.61 \pm 1.03$ \\
\hline UKF-NB-3 $3^{\mathrm{iG} 2(8)}$ & wild-type & - & $5.31 \pm 0.88$ \\
\hline UKF-NB-3 $3^{\text {p53hhRNA (9) }}$ & depleted & - & $3.53 \pm 0.69$ \\
\hline UKF-NB-3 $3^{\text {scrshRNA (10) }}$ & wild-type & - & $4.71 \pm 0.73$ \\
\hline UKF-NB-2 & wild-type & - & $3.74 \pm 0.48$ \\
\hline UKF-NB-2 $^{r} \mathrm{VCR}^{10}$ & wild-type & + & $6.67 \pm 1.25$ \\
\hline KFR & wild-type & - & $5.04 \pm 0.84$ \\
\hline $\mathrm{KFR}^{\mathrm{r} V C R}{ }^{10}$ & wild-type & + & $4.52 \pm 0.71$ \\
\hline Rh30 & mut (R273C) & - & $6.84 \pm 0.96$ \\
\hline $\mathrm{Rh} 0^{\mathrm{r}} \mathrm{VCR}^{10}$ & mut (R273C) & + & $8.20 \pm 1.07$ \\
\hline
\end{tabular}

${ }^{(1)}$ concentration that reduces cell viability (determined by MTT assay) after a 5 day incubation period by $50 \%$; ${ }^{(2)} \mathrm{ABCB} 1$ expression levels are presented in Suppl. Table 6; ${ }^{(3)}$ Values are mean \pm S.D.; ${ }^{(4)}$ mut=mutated, kind of mutation in brackets; ${ }^{(5)}$ UKF-NB-3 cells transduced with a lentiviral vector encoding for the $A B C B 1$ gene; ${ }^{(6)}$ UKF-NB-3 cells transduced with an empty lentiviral control vector, serving as transduction control for UKF-NB-3 ${ }^{\mathrm{ABCB}}$; ${ }^{(7)} \mathrm{UKF}-\mathrm{NB}-3$ cells transduced with a lentiviral vector encoding for the $A B C G 2$ gene; ${ }^{(8)} \mathrm{UKF}-\mathrm{NB}-3$ cells transduced with an empty lentiviral control vector, serving as transduction control for UKF-NB-3 ${ }^{\mathrm{ABCG} 2}$; ${ }^{(9)} \mathrm{UKF}-\mathrm{NB}-3$ cells transduced with a lentiviral vector encoding for shRNA directed against p53; ${ }^{(10)}$ UKF-NB-3 cells transduced with a lentiviral vector encoding scrambled (non-targeted) shRNA.

\section{Table 2: Enzastaurin concentrations that reduce viability of primary MYCN-amplified neuroblastoma cells by $\mathbf{5 0 \%}\left(\mathrm{IC}_{50}\right)$}

\begin{tabular}{|l|c|}
\hline \multicolumn{2}{|c|}{$\mathbf{I C}_{\mathbf{5 0}}(\boldsymbol{\mu M})$} \\
\hline isolate 1 & $6.2 \pm 2.3$ \\
\hline isolate 2 & $4.4 \pm 1.3$ \\
\hline isolate 3 & $3.3 \pm 1.4$ \\
\hline isolate 4 & $7.6 \pm 2.9$ \\
\hline
\end{tabular}

(Suppl. Figure 1A). PKC $\alpha$ was present, and siRNAmediated PKC $\alpha$ depletion inhibited PKC signalling as indicated by decreased levels of phosphorylated MARCKS (Figure 2B, Suppl. Figure 1B). However, siRNA-mediated depletion of PKC $\alpha$ did (in contrast to $\mathrm{ABCB} 1$ depletion) not increase rhodamine 123 accumulation in or vincristine sensitivity of ABCB1-expressing UKF-NB-3rVCR10 cells (Figure 2C, Suppl. Figure 1C). Similar results were obtained in UKF-NB-3 ${ }^{\mathrm{ABCB} 1}$ cells (Suppl. Figure 2A-2C).

After incubation of UKF-NB-3 ${ }^{r} \mathrm{VCR}^{10}$ cells with rhodamine 123 and enzastaurin, the wash-out of extracellular enzastaurin (and rhodamin 123) resulted in a rapid decrease of cellular rhodamine 123 fluorescence in a similar fashion like the wash out of the known ABCB1 substrate verapamil (Figure $3 \mathrm{~A}$ ). In addition, enzastaurin $0.3125 \mu \mathrm{M}$ significantly increased ABCB1 ATPase activity (Figure 3B). The combination of enzastaurin and verapamil further enhanced ABCB1 ATPase activity (Figure $3 \mathrm{C}$ ). Taken together, these data suggest that enzastaurin interferes with $\mathrm{ABCB} 1$ predominantly through direct interaction with $\mathrm{ABCB} 1$, possibly being an $\mathrm{ABCB} 1$ substrate. 


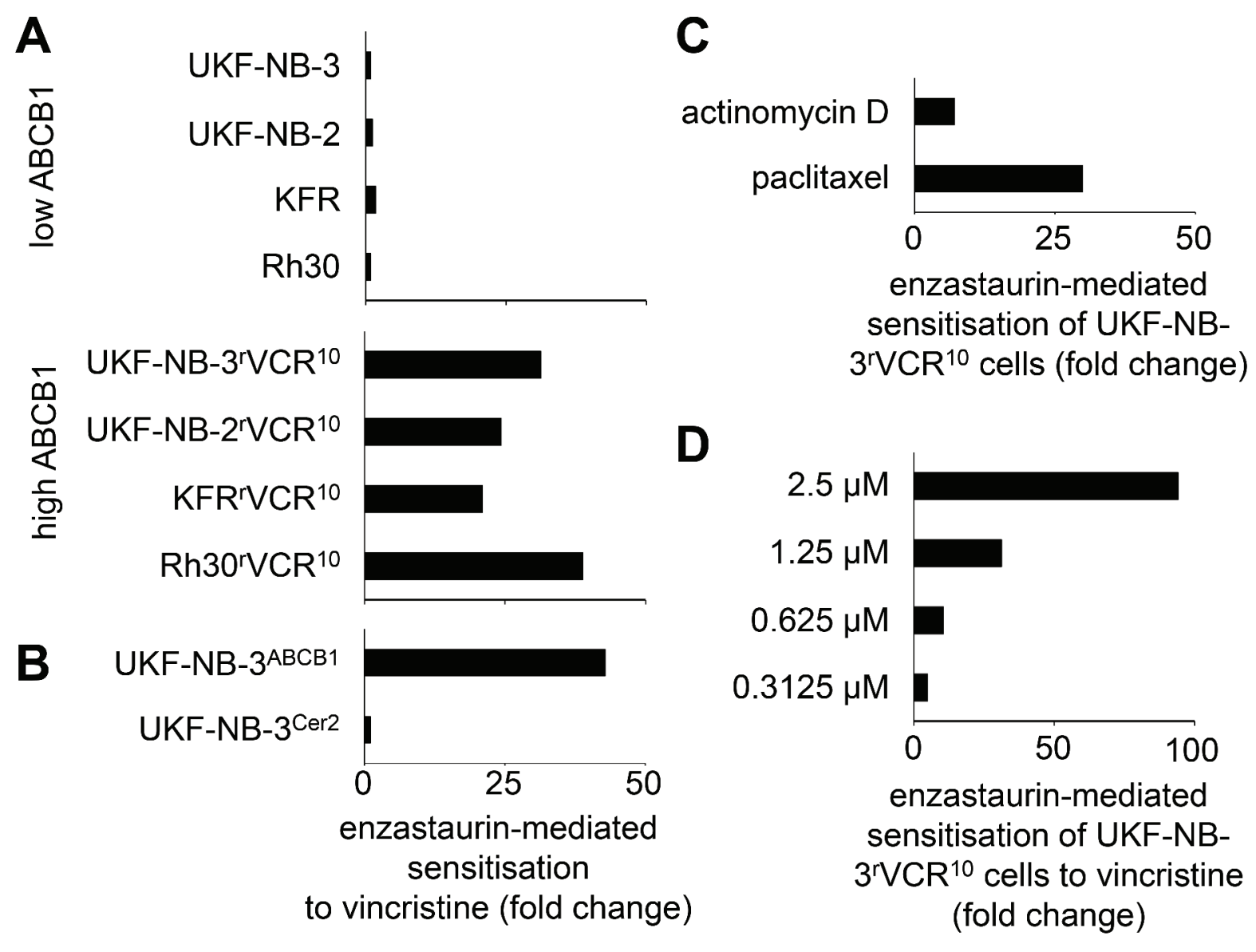

E

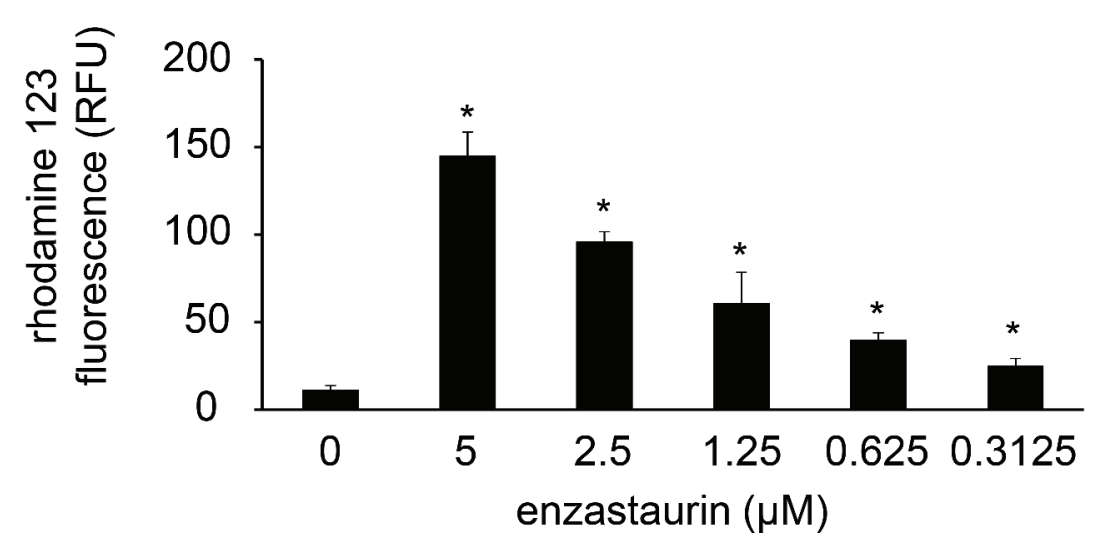

Figure 1: Influence of enzastaurin on drug sensitivity in ABCB1-expressing cells. (A) Sensitisation of low and high $A B C B 1$ expressing cells to the $\mathrm{ABCB} 1$ substrate vincristine by enzastaurin $1.25 \mu \mathrm{M}$, a concentration that did not influence viability of the investigated cell lines (fold change $\mathrm{IC}_{50}$ vincristine/ $\mathrm{IC}_{50}$ vincristine in the presence of enzastaurin); (B) sensitisation of UKF-NB-3 cells transduced with a lentiviral vector encoding for $A B C B 1$ (UKF-NB-3 ${ }^{\mathrm{ABCB} 1}$ ) or an empty control vector (UKF-NB-3 ${ }^{\text {Cer2 } 2) ~ t o ~ v i n c r i s t i n e ~ b y ~ e n z a s t a u r i n ~} 1.25 \mu \mathrm{M}$ (fold change $\mathrm{IC}_{50}$ vincristine/ $\mathrm{IC}_{50}$ vincristine in the presence of enzastaurin). Numerical data for A) and B) are presented in Suppl. Table 1. (C) Sensitisation of UKF-NB-3 ${ }^{\mathrm{r} V C R}{ }^{10}$ cells to the cytotoxic ABCB1 substrates actinomycin D and paclitaxel by enzastaurin $1.25 \mu \mathrm{M}$ (fold change $\mathrm{IC}_{50}$ drug alone/ $\mathrm{IC}_{50}$ drug in the presence of enzastaurin). Numerical data are presented in Suppl. Table 2. (D) Sensitisation of UKF-NB-3 ${ }^{\mathrm{r}} \mathrm{VCR}{ }^{10}$ cells to vincristine by enzastaurin (fold change $\mathrm{IC}_{50}$ vincristine $/ \mathrm{IC}_{50}$ vincristine in the presence of enzastaurin). Numerical data are presented in Suppl. Table 3. (E) Influence of enzastaurin on accumulation of rhodamine $123(0.5 \mu \mathrm{M}$; a fluorescent $\mathrm{ABCB} 1$ substrate) in $\mathrm{ABCB} 1$-expressing UKF-NB- $3^{\mathrm{r}} \mathrm{VCR}^{10}$ cells as detected by flow cytometry (RFU = relative fluorescence units). $* P<0.05$ relative to rhodamine alone. 


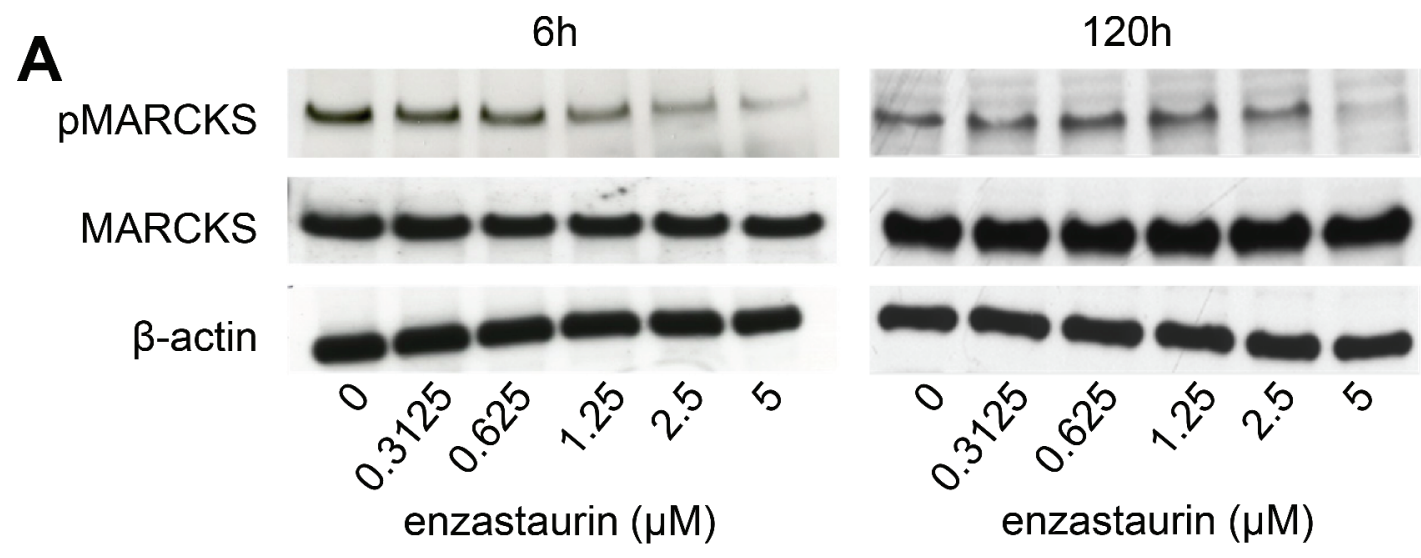

B

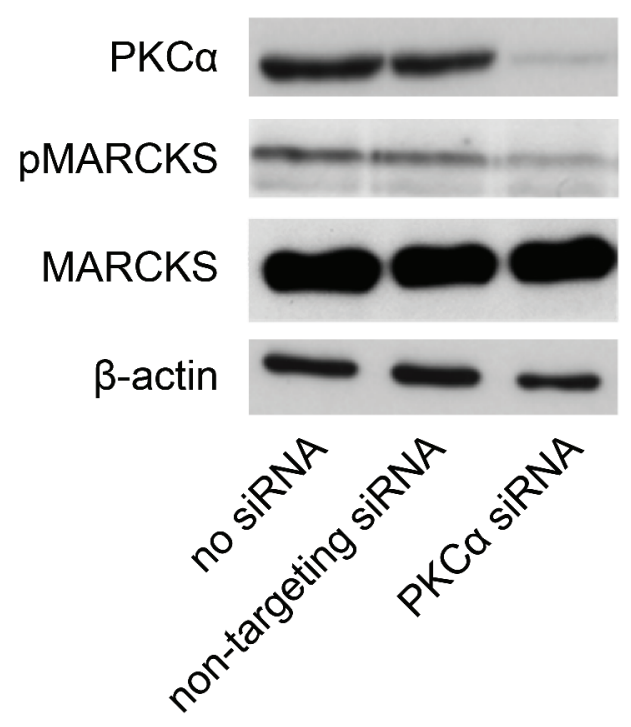

C

rhodamine 123

fluorescence

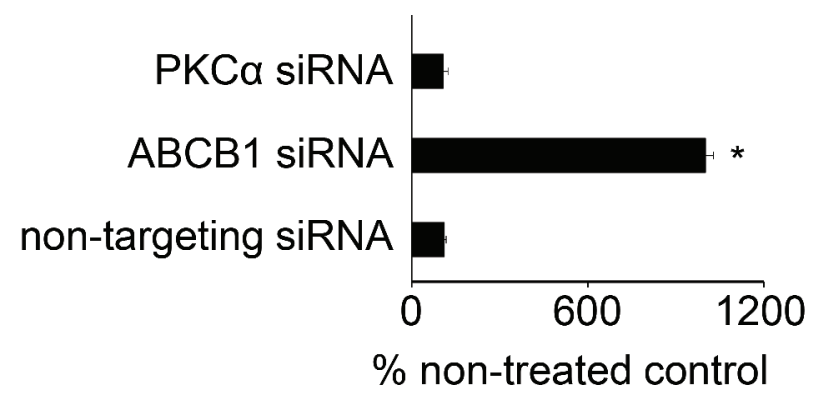

viability in the presence of vincristine $(40 \mathrm{ng} / \mathrm{mL})$

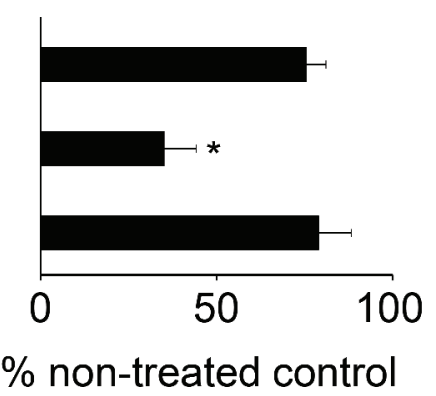

Figure 2: Investigation of PKC signalling. (A) Enzastaurin inhibits PKC activity in concentrations $\geq 1.25 \mu M$ in UKF-NB-3 ${ }^{\mathrm{r} V C R}{ }^{10}$ cells after enzastaurin treatment for $6 \mathrm{~h}$ and in a concentration of $5 \mu \mathrm{M}$ after $120 \mathrm{~h}$. Western blots indicate protein levels of the PKC target MARCKS, its phosphorylated form (pMARCKS), and $\beta$-actin (loading control). Effects on ABCB1 function were observed at an enzastaurin concentration of $0.3125 \mu \mathrm{M}$ (Figure 1D, Suppl. Table 3). (B) Effects of siRNA-mediated PKC $\alpha$ depletion on MARCKS phosphorylation determined in UKF-NB- $3^{r} V_{C R}{ }^{10}$ cells $48 \mathrm{~h}$ after transfection; (C) siRNA directed against ABCB1 (but not siRNA directed against $\mathrm{PKC} \alpha$ ) increases (1) accumulation of the fluorescent ABCB1 substrate rhodamine $123(0.5 \mu \mathrm{M})$ in ABCB1-expressing UKF-NB$3^{r} \mathrm{VCR}^{10}$ cells and (2) the sensitivity of UKF-NB- $3^{\mathrm{r}} \mathrm{VCR}^{10}$ cells to the cytotoxic ABCB1 substrate vincristine. Effects of siRNAs on ABCB1 expression are presented in Suppl. Figure 1. $(* P<0.05)$ relative to non-targeting siRNA. 


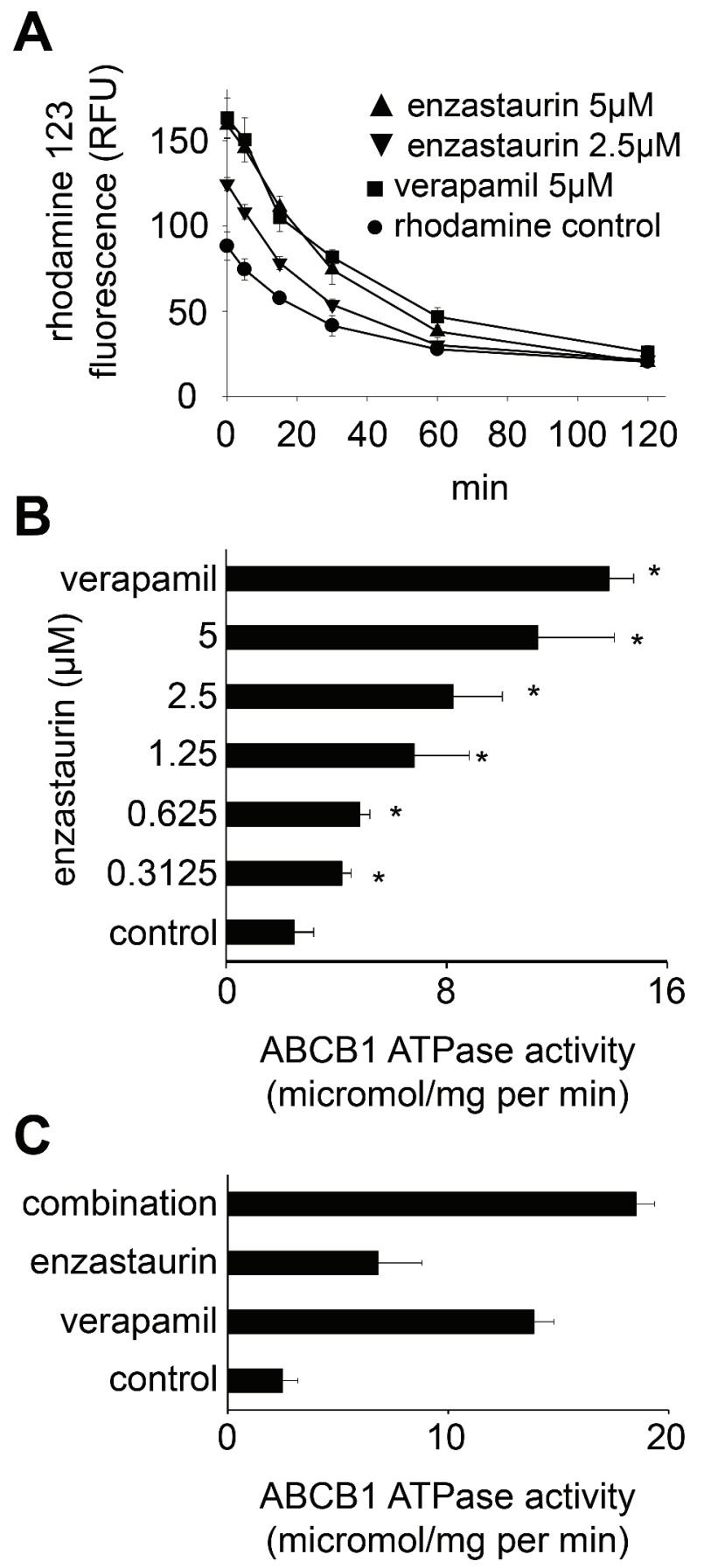

Figure 3: Direct interaction of enzastaurin with ABCB1. (A) Time kinetics of rhodamine $123(0.5 \mu \mathrm{M})$ fluorescence in UKF-NB$3^{\mathrm{r}} \mathrm{VCR}^{10}$ cells after incubation for $60 \mathrm{~min}$ with rhodamine 123 alone (rhodamine control), enzastaurin $5 \mu \mathrm{M}$ or $2.5 \mu \mathrm{M}$ plus rhodamine 123 , or verapamil $5 \mu \mathrm{M}$ (known ABCB1 substrate serving as control) plus rhodamine 123 after wash-out as detected by flow cytometry (RFU = relative fluorescence units). ${ }^{*} P<0.05$ relative to rhodamine alone; (B) ABCB1 ATPase activity in isolated membranes in the presence of verapamil $5 \mu \mathrm{M}$ or enzastaurin. ${ }^{*} P<0.05$ relative to non-treated control; (C) ABCB1 ATPase activity in non-treated isolated membranes or in the presence of verapamil $5 \mu \mathrm{M}$, enzastaurin $1.25 \mu \mathrm{M}$, or the combination of verapamil $5 \mu \mathrm{M}$ and enzastaurin $1.25 \mu \mathrm{M}$. $* P<0.05$ relative to single treatment with verapamil and enzastaurin.

\section{Docking experiments suggest a direct interaction of enzastaurin with $\mathrm{ABCB} 1$}

Enzastaurin was docked into the homology model of human $\mathrm{ABCB} 1$ and the three $\mathrm{x}$-ray structures of mouse
Abcb1a, with the binding sites defined using the positions of the co-crystallised ligands, QZ59-RRR and QZ59-SSS, and the verapamil binding site (residues protected from methanethiosulfonate (MTS) labelling by verapamil) as described by Aller et al. [36]. Results indicate a strong 
interaction between enzastaurin and ABCB1. The docking scores for the top five docking poses ranged between -16.60 and $-9.01 \mathrm{kcal} / \mathrm{mol}$ for mouse, and between -13.30 and $-10.42 \mathrm{kcal} / \mathrm{mol}$ for human ABCB1 (Suppl. Table 4). Docking enzastaurin into 3G60 and 3G61 generated the lowest binding scores. The protein structures 3G61 and 3G60 are the structures co-crystallised with QZ59-SSS and QZ59-RRR respectively, and have a $x$-ray resolutions of $4.35 \AA$ and $4.40 \AA$. $3 \mathrm{G} 5 \mathrm{U}$ is the apo-structure with a higher $\mathrm{x}$-ray resolution of $3.80 \AA$. Suppl. Table 4 also shows that the best binding scores in all cases are achieved when the biding site is defined using the co-crystallised QZ59-SSS (see the average of the top five poses in Suppl. Table 4). The only exception to this is the top pose obtained for 3G60 when docked into QZ59-RRR binding site. The energy of the top pose can be as low as -16.60 when the binding site residues of QZ59-RRR have been selected to define the binding pocket for enzastaurin (Suppl. Table 4).

Suppl. Table 5 shows the ligand interaction report indicating specific interactions between structural elements of the enzastaurin structure and ABCB1 residues in the top docking poses. A summary of the residues involved in the enzastaurin interaction with mouse Abcbla has been plotted in Figure 4A. The figure indicates that the most prevalent interacting residues in mouse Abcbla are Phe71, Phe728, and Phe974. Notably, Phe728 and Phe974 are the amino acids reported by Aller et al. [36] to be involved in the QZ59-RRR binding site. These three Phe residues are mostly involved in $\pi-\pi$ interactions, with fewer occurrences of $\pi$-H or $\pi$-cation interactions with the ligand (Suppl. Table 5). An example of a top scoring docking pose for the interaction of enzastaurin with mouse Abcb1a is shown in Figure 4B. The Phe residues 71, 728 and 974 are present in the binding site with the shadows indicating that in the absence of the ligand these amino acids are highly exposed to the solvent, but the presence of the ligand greatly reduces the solvent accessible surface area (Figure 4B). In addition, there are several other lipophilic residues in the close proximity of the ligand with receptor exposure shadows indicating the possibility of several hydrophobic interaction points (Figure 4B). The pyridine ring in the ligand has a strong arene- $\mathrm{H}$ interaction with Gln721, while the pyrrole ring is engaged in H-bonding interaction with Ser975 (Figure 4).

\section{Effects of enzastaurin on ABCG2}

Finally, we showed that enzastaurin also concentration-dependently sensitised ABCG2-transduced UKF-NB-3 (UKF-NB-3 ${ }^{\mathrm{ABCG} 2}$ ) cells (but not UKF-NB-3 or control vector-transduced UKF-NB-3 ${ }^{\mathrm{iG} 2}$ cells) to toxicity induced by the cytotoxic ABCG2 substrate mitoxantrone (Figure 5A, Suppl. Table 6A-6C). In addition, enzastaurin enhanced mitoxantrone accumulation in UKF-NB-3 $3^{\mathrm{ABCG} 2}$ cells but not in UKF-NB-3 $3^{\mathrm{iG} 2}$ cells as determined by flow cytometry (Figure 5B; Suppl. Figure 3). While enzastaurin had enhanced ABCB1 ATPase activity, it inhibited basal and sulfasalazineinduced $\mathrm{ABCG} 2$ activity (Figure $6 \mathrm{~A}$ and $6 \mathrm{~B}$ ) indicating that enzastaurin inhibits $\mathrm{ABCB} 1$ and $\mathrm{ABCG} 2$ activity through different mechanisms.

\section{DISCUSSION}

PKC signalling was reported to be relevant in neuroblastoma and rhabdomyosarcoma [37-40]. In this report, $\mathrm{IC}_{50}$ values between 3.7 and $8.2 \mu \mathrm{M}$ were determined for the PKC $\beta$ inhibitor enzastaurin in a panel of parental neuroblastoma and rhabdhomyosarcoma cell lines and their vincristine-resistant sub-lines and $\mathrm{IC}_{50} \mathrm{~S}$ between 3.3 and $9.5 \mu \mathrm{M}$ in primary neuroblastoma cells. These concentrations are in the range of those reported to be effective in other cancer entities $[2,6]$. Notably, enzastaurin activity was not affected by $\mathrm{ABC}$ transporters $\mathrm{ABCB} 1$ or $\mathrm{ABCG} 2$ or the cellular p53 status. With regard to $\mathrm{p} 53$, our results are in line with a recent study that showed that the effects of enzastaurin monotherapy did not differ between HCT116 $6^{\mathrm{p} 53 \mathrm{wt}}$ and $\mathrm{HCT}^{\mathrm{p} 53-/-}$ cells [41]. However, since enzastaurin plasma levels of $1-2$ $\mu \mathrm{M}$ were reported to be achievable in patients [14, 42], enzastaurin may rather not be a candidate for single therapy in neuroblastoma or rhabdomyosarcoma.

Enzastaurin concentrations as low as 0.3125 $\mu \mathrm{M}$ sensitised ABCB1-expressing cells (but not non$\mathrm{ABCB} 1$-expressing cells) to toxicity induced by the ABCB1 substrate vincristine. Enzastaurin also sensitised ABCB1-expressing cells to the structurally differing cytotoxic ABCB1 substrates paclitaxel and actinomycin D. Notably, enzastaurin exerted more pronounced effects on vincristine- and paclitaxel-mediated toxicity than on actinomycin D-induced toxicity. The exact molecular mechanisms underlying these differences are not clear. It is known that the mode and/or strength of ABCB1 interaction may differ among $\mathrm{ABCB} 1$ substrates and ABCB1 modulators. Certain ABCB1 modulators were shown to exert differing effects on the cellular accumulation of distinct ABCB1 substrates [43-45].

Moreover, enzastaurin caused a dose-dependent accumulation of the fluorescent ABCB1 substrate rhodamine 123 in ABCB1-expressing cells. Again, significant effects were determined at an enzastaurin concentration of $0.3125 \mu \mathrm{M}$. These data indicate that enzastaurin interferes with ABCB1-mediated drug transport. This is of potential clinical relevance. ABCB1 is expressed at virtually every tissue and organ barrier and influences the absorption, distribution, and excretion of drugs, xenobiotics, and food constituents [29, 31]. Therefore, enzastaurin may affect the pharmacokinetics of co-administered drugs including anti-cancer drugs and drugs non-related to cancer. Moreover, ABCB1 is frequently found highly expressed on cancer cells playing 


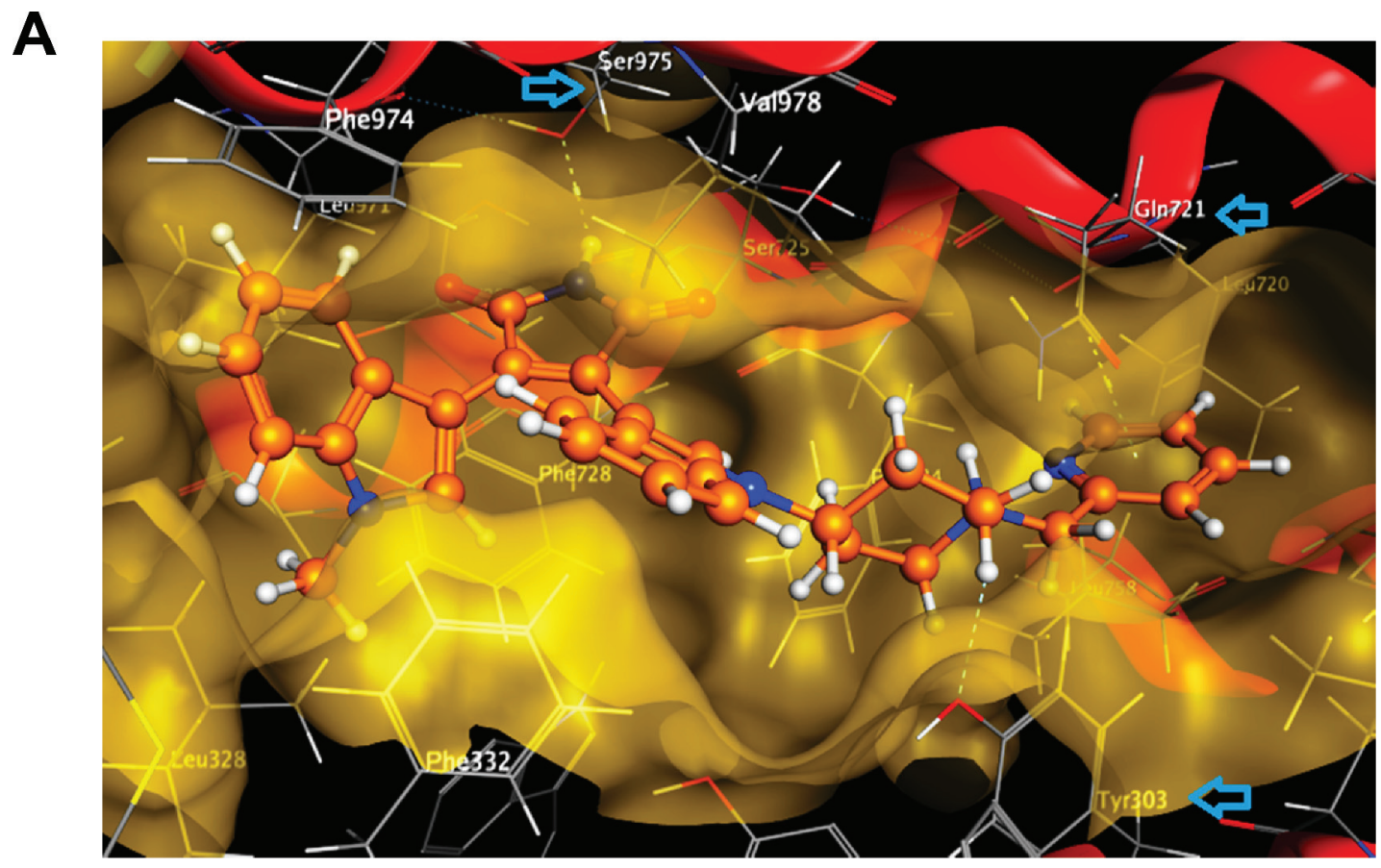

B

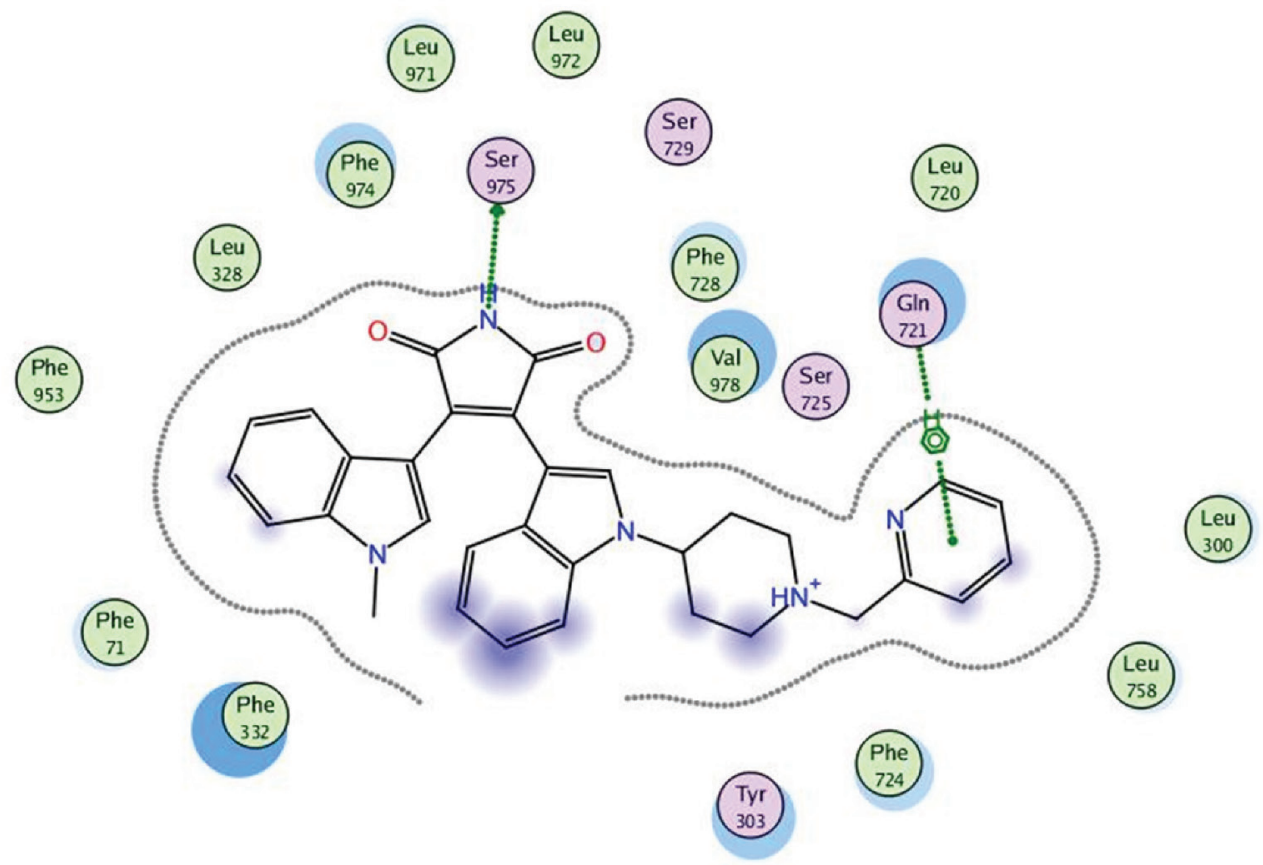

Figure 4: Interaction of enzastaurin with $\mathrm{ABCB} 1$ as indicated by docking experiments. (A) $3 \mathrm{D}$ view of a portion of the active site of mouse abc1b1 (3G60) at the lowest docking energy with docked enzastaurin in the binding pocket; blue arrows in this pose indicate residues (Ser925, Tyr303 and Gln721) that have strong interactions with enzastaurin (limited within 4.5 $\AA$ ); (B) 2D ligand interaction diagram for enzastaurin with mouse Abcbla using default settings of MOE software. The polar and non-polar residues are indicated by pink or green coloured amino acids respectively. Hydrogen bonding is indicated by green dotted arrow, while arene-H interaction is shown by green dotted line. The proximity contour is the dotted line surrounding the ligand. Blue shadows in of the residues indicate the receptor exposure differences by the size and intensity of the quoits discs. The directions of the shadow indicate the directions of the amino acids towards the ligands. The blue clouds around the ligand atoms indicate that are exposed to the solvent. 


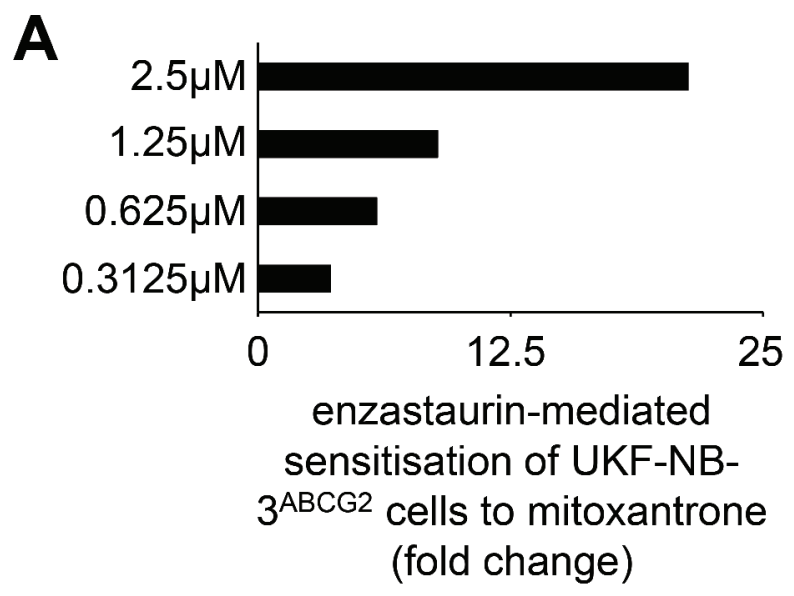

B

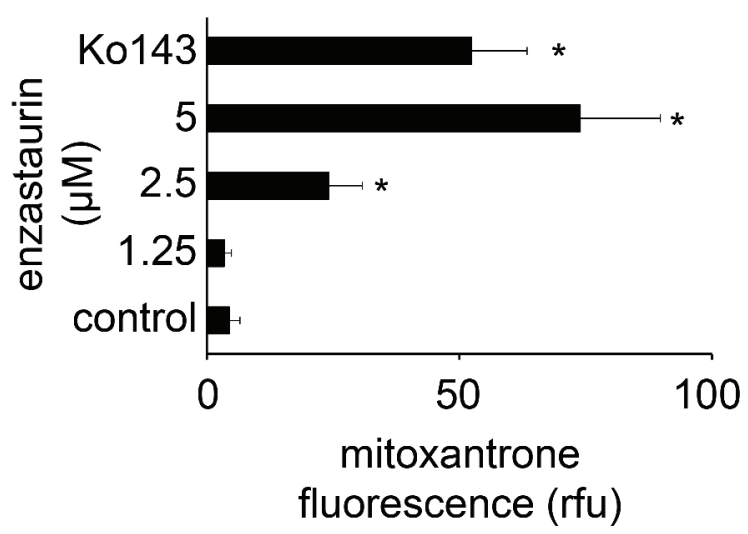

Figure 5: Influence of enzastaurin on ABCG2 function. (A) Sensitisation of UKF-NB-3 cells transduced with a lentiviral vector encoding for ABCG2 (UKF-NB-3 $3^{\mathrm{ABC} 2}$ ) to the ABCG2 substrate mitoxantrone by enzastaurin concentrations that did not influence UKF$\mathrm{NB}-3^{\mathrm{ABCG} 2}$ cell viability (fold change $\mathrm{IC}_{50}$ mitoxantrone/ $\mathrm{IC}_{50}$ mitoxantrone in the presence of enzastaurin), numerical data are presented in Suppl. Table 6; (B) Influence of enzastaurin on accumulation of mitoxantrone (40 $\mu \mathrm{M}$; a fluorescent ABCG2 substrate) in UKF-NB-3 $3^{\mathrm{ABCG} 2}$ cells as detected by flow cytometry (RFU = relative fluorescence units). The ABCG2 inhibitor Ko143 (1 $\mu \mathrm{M})$ served as positive control. $* P<0.05$ relative to mitoxantrone alone.

an important role in cancer cell drug resistance [30]. Seemingly, our data are in accordance with unpublished internal data from Eli Lilly [46].

Previous reports had shown that PKC $\alpha$ and $\mathrm{PKC} \beta$ may promote $\mathrm{ABCB} 1$ function by phosphorylation [34, $35]$. However, other data did not support this [47, 48], and further reports even suggested that PKC signalling may also decrease $\mathrm{ABCB} 1$ activity $[49,50]$. Our data do not suggest that $\mathrm{PKC} \alpha$ and/or PKC $\beta$ inhibition may play a dominant role in the observed effects on $\mathrm{ABCB} 1$ function in our system although some contribution of effects on PKC signalling cannot be excluded, in particular at higher enzastaurin concentrations. We did not observe PKC $\beta$ expression in UKF-NB- $3^{r} \mathrm{VCR}^{10}$ cells. PKC $\alpha$ depletion reduced MARCKS phosphorylation indicating inhibition of PKC signalling but did not affect $\mathrm{ABCB} 1$ function. Moreover, the enzastaurin $\mathrm{IC}_{50}$ for $\mathrm{PKC} \alpha$ inhibition in isolated enzyme assay is $0.8 \mu \mathrm{M}$ (1) and appears, thus, to be too high to explain effects on $\mathrm{ABCB} 1$ function in concentrations as low as $0.3125 \mu \mathrm{M}$. Also, enzastaurin-mediated inhibition of PKC signalling became only detectable at a concentration of 1.25 $\mu \mathrm{M}$ after $6 \mathrm{~h}$ of incubation or $5 \mu \mathrm{M}$ after $120 \mathrm{~h}$ of incubation. These concentrations are substantially higher than the low enzastaurin concentrations that affected ABCB1-mediated drug transport. In addition, wash-out experiments and determination of ABCB1 ATPase activity demonstrated that the enzastaurin-mediated effects closely resemble those of the $\mathrm{ABCB} 1$ substrate verapamil. Therefore, enzastaurin appears to interfere directly with $\mathrm{ABCB} 1$, possibly being an $\mathrm{ABCB} 1$ substrate. This finding is in concordance with data showing that staurosporine, the lead structure that provided the basis for the synthesis of enzastaurin [1], and staurosporine analogues may interfere with $\mathrm{ABCB} 1$ function independently of effects on PKC signalling [43].

In a head-to-head comparison of enzastaurin with staurosporine and its derivatives UCN-01, GF109203X, and RO-31-8220 that had previously been investigated for their interaction with $\mathrm{ABCB} 1$-mediated drug transport [43], enzastaurin exerted similar effects on rhodamine 123 accumulation in $\mathrm{ABCB} 1$-transduced UKF-NB-3 ${ }^{\mathrm{ABCB} 1}$ cells 

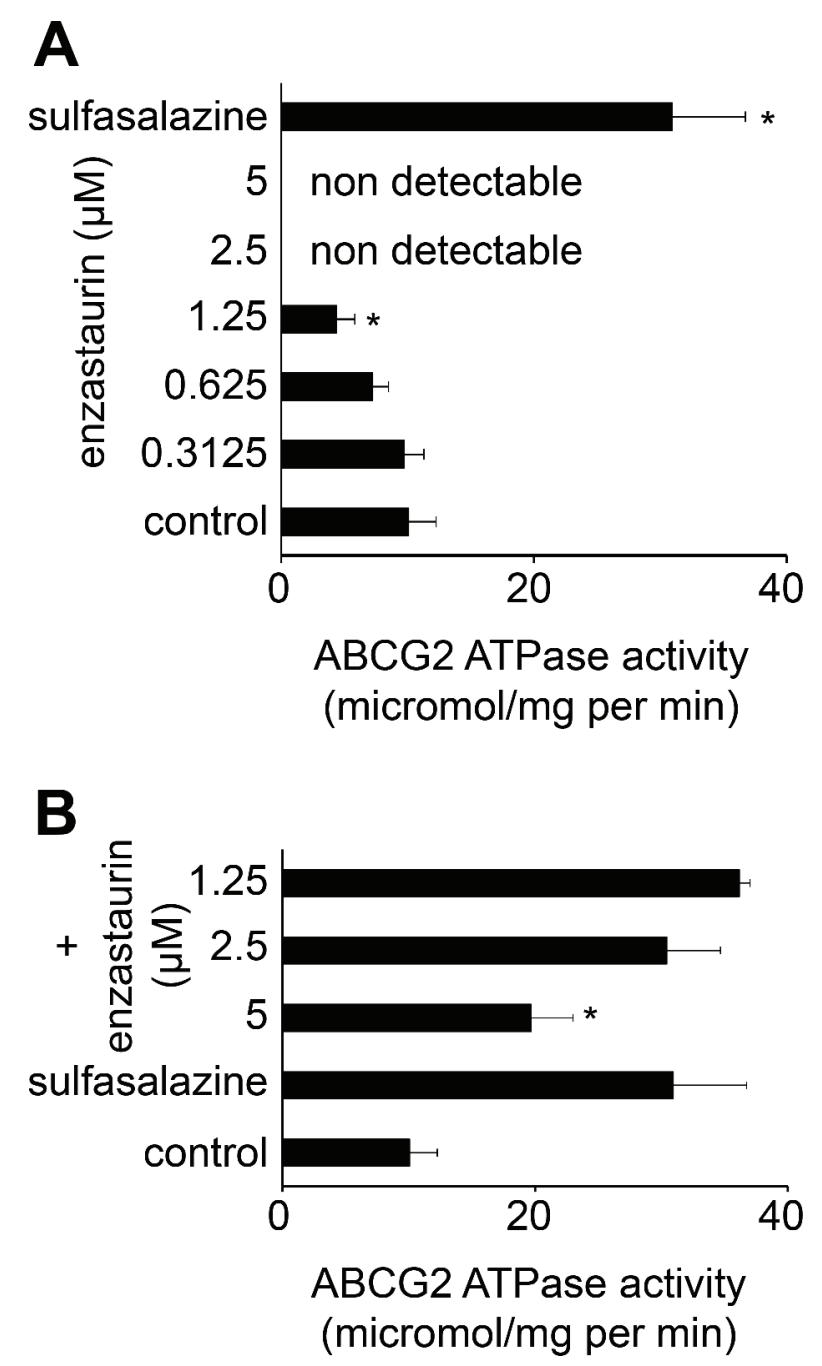

Figure 6: Effects of enzastaurin on the ABCG2 ATPase. (A) ABCG2 ATPase activity in isolated membranes in the presence of enzastaurin or the ABCG2 substrate sulfasalazine $10 \mu \mathrm{M}$. $* P<0.05$ relative to non-treated control; (B) ABCG2 ATPase activity in nontreated isolated membranes or in the presence of sulfasalazine $10 \mu \mathrm{M}$ alone or in combination with enzastaurin. ${ }^{*} P<0.05$ relative to single treatment with sulfasalazine.

like staurosporine and UCN-01 that had previously been shown to interfere strongly with ABCB1-mediated drug transport [43]. Also in concert with previous findings [43], GF109203X and RO-31-8220 displayed substantially weaker or no effects on rhodamin 123 accumulation (Suppl. Figure 4A and 4B). Moreover, enzastaurin exerted stronger effects on rhodamin 123 accumulation than verapamil in a direct comparison (Suppl. Figure 4A and 4B).

The notion that enzastaurin interacts directly with ABCB1 is further supported by computational docking studies. Recent analyses had shown that docking studies performed by various approaches are reliable strategies to identify compounds that interact directly with ABCB1 [51-53]. From our previous studies, the docking scores obtained for a group of 54 substrates (including well-known substrates such as ivermectin and cyclosporine) had an average docking score of $\leq-12$, like those we observed for enzastaurin in the 3G60 structure, while a group of 69 non- substrates had an average score of $\sim-10 \mathrm{kcal} / \mathrm{mol}$ using MOE software and the same docking methodology [54, 55].

Notably, the effects of PKC signalling on ABCB1 phosphorylation and function appear to be cell typedependent. In ovarian carcinoma cells, antisense oligomers directed against PKC $\alpha$ and $\mathrm{PKC} \beta$ reversed $\mathrm{ABCB} 1-$ mediated drug resistance [56]. In contrast, $\mathrm{PKC} \beta$ was not detectable in our model system, and siRNAs targeting $\mathrm{PKC} \alpha$ interfered with $\mathrm{PKC}$ signalling but not with $\mathrm{ABCB} 1$ function. Moreover, $\mathrm{p} 53$ was shown to suppress $\mathrm{PKC} \alpha$-mediated $\mathrm{ABCB} 1$ activation in leiomyosarcoma, fibrosarcoma, and osteosarcoma cells [35]. In contrast, the enzastaurin-mediated effects on ABCB1 function did not differ between $\mathrm{p} 53$ wild-type and p53-mutant neuroblastoma or rhabdomyosarcoma cells in the present study.

In addition to its interaction with $\mathrm{ABCB} 1$, enzastaurin interfered with ABCG2-mediated drug transport but the mode of action appears to be different. 
While enzastaurin stimulated ABCB1 ATPase activity, it inhibited ABCG2 ATPase activity. ABCC1 (also known as MRP1) is another $\mathrm{ABC}$ transporter that is known to be of clinical relevance in neuroblastoma [57]. Noteworthy, enzastaurin also sensitised ABCC1-expressing cells to the $\mathrm{ABCC} 1$ substrate vincristine and enhanced accumulation of the fluorescent ABCC1 substrate 5-CFDA in ABCC1expressing cells (Suppl. Figure 5A-5C). Our findings showing that enzastaurin interferes with ABCB1-, ABCG2-, and ABCC1-mediated drug transport are of relevance for the further development of enzastaurin combination therapies. Enzastaurin has been reported to display enhanced activity in combination with various anti-cancer drugs [see e.g. 11, 13, 17, 19, 41; 58-60] including $\mathrm{ABCB} 1, \mathrm{ABCG} 2$, and/or $\mathrm{ABCC} 1$ substrates such as paclitaxel [60], docetaxel [58], erlotinib [59], and doxorubicin [11]. In the light of the finding that enzastaurin interferes with the ABCB1-, ABCG2-, and $\mathrm{ABCC} 1-$ mediated drug transport studies that investigate the combined use of enzastaurin with substrates of these transporters may require careful (re-)evaluation.

In conclusion, our data show that enzastaurin inhibits $\mathrm{ABCB} 1$ predominantly through direct interaction independently of effects on PKC signalling or the cellular p53 status. This finding is in particular relevant for the further development of therapies in which enzastaurin is combined with ABCB1 substrates.

\section{MATERIALS AND METHODS}

\section{Drugs}

Enzastaurin was purchased from Selleck Chemicals via BIOZOL GmbH (Eching, Germany). Vincristine was obtained from Sigma-Aldrich Chemie GmbH (Munich, Germany). Rhodamine 123 was purchased from Merck Biosciences (Darmstadt, Germany).

\section{Cell culture}

The MYCN-amplified neuroblastoma cell lines UKFNB-2 and UKF-NB-3 were established from INSS stage 4 neuroblastoma patients $[61,62]$. The rhabdomyosarcoma cell line Rh30 was kindly provided by Dr. P.J. Houghton (St. Jude's Children's Research Hospital, Memphis, $\mathrm{TN})$. The alveolar rhabdomyosarcoma cell line KFR was established from a bone marrow metastasis [63]. K562 cells were obtained from ATCC (Manassas, VA, USA).

The cell lines were adapted to growth in the presence of vincristine $10 \mathrm{ng} / \mathrm{ml}$ and named UKF-NB-2 ${ }^{\mathrm{r}} \mathrm{VCR}^{10}[61]$, UKF-NB-3 ${ }^{\mathrm{r}} \mathrm{VCR}^{10}$ [62], Rh30 ${ }^{\mathrm{r}} \mathrm{VCR}^{10}$ [64], KFR ${ }^{\mathrm{r} V C R}{ }^{10}$ and derived from the RCCL collection (http://www.kent. ac.uk/stms/cmp/RCCL/RCCLabout.html).

The UKF-NB-3 sub-lines expressing ABCB1 (UKF-NB-3 ${ }^{\mathrm{ABCB} 1}$ ), ABCG2 (also known as BCRP, UKFNB-3 ${ }^{\mathrm{ABCG} 2}$ ), or shRNA targeting p53 mRNA (UKF-NB- $3^{\text {p53shRNA }}$ ) were established by lentiviral transfection as described previously [65-68] (http://www.lentigo-vectors. de). ABCB1 expression data for the project cell lines is presented in Suppl. Figure 6.

Fresh neuroblastoma cells (MYCN amplified) were isolated from the bone marrow aspirate of patients with metastasised INSS stage 4 neuroblastoma.

Cells were propagated in IMDM supplemented with $10 \%$ foetal calf serum, $100 \mathrm{IU} / \mathrm{ml}$ penicillin and $100 \mathrm{mg} /$ $\mathrm{ml}$ streptomycin at $37^{\circ} \mathrm{C}$.

\section{Viability assay}

Cell viability was tested by the 3-(4,5-dimethylthiazol2-yl)-2,5-diphenyltetrazolium bromide (MTT) dye reduction assay after $120 \mathrm{~h}$ incubation modified as described before [64].

\section{$\mathrm{ABC}$ transporter expression and function}

Antibodies directed against ABCB1 (Alexis Biochemicals via AXXORA Deutschland, Lörrach, Germany) or ABCG2 (Kamiya Biomedical Company, Seattle, WA, USA), followed by a secondary antibody labelled with Phycoerythrin (R\&D, Wiesbaden, Germany) were used to detect protein expression by flow cytometry (FACSCalibur, BD Biosciences, Heidelberg, Germany).

To investigate ABCB1-mediated drug efflux, cells were pre-incubated with different concentrations of enzastaurin for $30 \mathrm{~min}$. $0.5 \mu \mathrm{M}$ rhodamine 123 (fluorescent ABCB1 substrate) was added for another $30 \mathrm{~min}$. Then, cell culture medium was removed, cells were washed three times with PBS, and fresh medium containing enzastaurin was added. After another $45 \mathrm{~min}$, cellular fluorescence was analysed by flow cytometry (FACSCalibur). Rhodamine 123 was detected at the FL1 channel.

For wash out kinetic experiments, cells were incubated for $1 \mathrm{~h}$ with $0.5 \mu \mathrm{M}$ rhodamine 123 and enzastaurin at the indicated concentrations. Cells were resuspended in supplemented medium and cellular fluorescence was measured after different time points $\left(t_{0}, t_{5}\right.$, $\mathrm{t}_{15}, \mathrm{t}_{30}, \mathrm{t}_{60}, \mathrm{t}_{120}$ minutes) by flow cytometry (FACSCalibur).

To investigate ABCG2-mediated drug efflux, the same procedures were carried out. Mitoxantrone served as fluorescent and cytotoxic ABCG2 substrate. The ABCG2 inhibitor Ko143 [69] was used as control substance.

The ATPase activities of ABCB1 and ABCG2 were determined using membrane preparations (ABCB1Membran: BD Biosciences, Heidelberg, Germany; ABCG2 membrane: Solvo Biotechnolgy, Budapest, Hungary) and an established kit (BD Biosciences, Heidelberg, Germany) following the manufacturer's instruction.

\section{PKCa expression}

Antibodies directed against PKC $\alpha$ (abcam, Cambridge, UK) followed by a secondary antibody 
labelled with Phycoerythrin (R\&D, Wiesbaden, Germany) were used to detect protein expression by flow cytometry (FACSCalibur, BD Biosciences).

\section{Western blot}

Cells were lysed in Triton X-sample buffer and separated by SDS-PAGE. Proteins were detected using specific antibodies directed against $\beta$-actin (BioVision via BioCat GmbH, Heidelberg, Germany), PKC $\alpha$ (abcam, Cambridge, UK), PKC $\beta$ (BD Biosciences, Heidelberg, Germany), MARCKS (Cell Signaling Technology, Danvers, MA), and phosphorylated MARCKS (Cell Signaling Technology). Protein bands were visualised by enhanced chemiluminescence using a commercially available kit (Amersham, Freiburg, Germany).

\section{siRNA transfection experiments}

Synthetic siRNA oligonucletides targeting ABCB1 or PRKCA (encoding for PKC $\alpha$ ) (ON-TARGET plusSMART pool siRNAs) were purchased from Dharmacon (Lafayette, CO, USA). The non targeting siRNA ON-TARGET plus SMART pool (Dharmacon) was used as negative control. Transfections were performed using the Neon ${ }^{\mathrm{TM}}$ Transfection System (Invitrogen, Darmstadt, Germany) according to the manufacturer's protocol. UKF-NB- $3^{\mathrm{r}} \mathrm{VCR}^{10}$ or UKF-NB-3 $3^{\mathrm{ABCB} 1}$ cells were grown to about $60-80 \%$ confluence, trypsinised and $2 \times$ $10^{6}$ cells were re-suspended in $200 \mu \mathrm{l}$ re-suspension buffer containing $2.5 \mu \mathrm{M}$ siRNA. Electroporation was performed in a pipette tip chamber with previously optimised adjustments (voltage 1400, width 20ms, 2 pulses). After electroporation, the cells were transferred into fibronectin $(100 \mu \mathrm{g} / \mathrm{ml})$-coated 6-well-plates containing pre-warmed IMDM plus $10 \%$ foetal calf serum.

\section{ABCB1 docking studies}

The protein and ligands were prepared for docking in MOE (version 2012.10, Chemical Computing Group Inc., Montreal, Canada). Mouse Abcbla structures, $3 \mathrm{G} 60,3 \mathrm{G} 61$ and $3 \mathrm{G} 5 \mathrm{U}$ [36] were obtained from the protein data bank (http://www.rcsb.org), the human homology model based on this structure from [70]. The crystal parameters were retained and all atoms of $\mathrm{ABCB} 1$ were protonated and titrated using default parameters of the software.

To prepare the ligand for docking, atomic charges were initially calculated using Merck Molecular Force Field 94 (MMFF94) force field and then the energy was minimised and atomic charges were re-calculated using Self-Consistent Field (SCF) optimization (AM1 Hamiltonian). Several docking experiments were performed for each protein using the binding site defined by proximity to a co-crystallised ligand and the residues reported by Aller et al. [36] to be involved in the binding pocket of cyclic-tris-(R)-valineselenazole (QZ59-RRR), upper binding pocket of cyclic-tris-(S)-valineselenazole (QZ59-SSS), lower binding pocket of QZ59-SSS, or the verapamil binding site (residues protected from MTS labelling by verapamil) as described by Aller et al [36].

In the MOE dock panel, the placement method was Triangle Matcher, scoring methodology was set to London $\mathrm{dG}$ as the first and the second scoring functions, and the final energy was evaluated using the Generalized Born solvation model (GB/VI) and finally, the top five best scoring poses were retained.

Default parameters of the software were used for the calculation of the ligand interactions. These were energy cut-off for $\mathrm{H}$-bonding and ionic interactions at $-0.5 \mathrm{kcal} / \mathrm{mol}$ and the maximum distance for non-bonded interactions at $4.5 \AA$. This docking methodology has been validated previously by docking the co-crystallised ligand, QZ59-RRR and comparing the geometries of the 'docked ABCB1/QZ59-RRR' structure with the structure of P-gp/QZ59-RRR complexes from x-ray crystallography [71]. The docking methodology using MOE has a built in conformational search that conducts a systematic search covering all combinations of angles on a grid if this will result in under 5000 conformers. Otherwise a stochastic sampling of conformations is conducted. In addition to this automatic conformational search in one of the docking experiments for each protein, we performed a prior conformational analysis before the docking and used all the resulting conformations. MOE conformational search was used with LowModeMD sampling method. This sampling method has been suggested as the method of choice for larger flexible compounds and macrocycles [70]. Using the default settings of the software, 74 different conformations were generated and used in one docking experiment for each of the proteins.

\section{Statistics}

Results are expressed as mean \pm S.D. of at least three experiments. Comparisons between two groups were performed using Student's $t$-test. Three and more groups were compared by ANOVA followed by the StudentNewman-Keuls test. $P$ values lower than 0.05 were considered to be significant.

\section{ACKNOWLEDGMENT}

The authors thank Kristoffer Riecken and Boris Fehse for support with the lentiviral vectors. The work was supported by the Hilfe für krebskranke Kinder Frankfurt e.V., the Frankfurter Stiftung für krebskranke Kinder, and the Kent Cancer Trust. 


\section{REFERENCES}

1. Faul MM, Gillig JR, Jirousek MR, Ballas LM, Schotten T, Kahl A, Mohr M. Acyclic N-(azacycloalkyl)bisindolylmaleimides: isozyme selective inhibitors of PKCbeta. Bioorg Med Chem Lett. 2003; 13:1857-1859.

2. Graff JR, McNulty AM, Hanna KR, Konicek BW, Lynch RL, Bailey SN, Banks C, Capen A, Goode R, Lewis JE, Sams L, Huss KL, Campbell RM, et al. The protein kinase Cbeta-selective inhibitor, Enzastaurin (LY317615.HCl), suppresses signaling through the AKT pathway, induces apoptosis, and suppresses growth of human colon cancer and glioblastoma xenografts. Cancer Res. 2005; 65:7462-7469.

3. Moreau AS, Jia X, Ngo HT, Leleu X, O'Sullivan G, Alsayed Y, Leontovich A, Podar K, Kutok J, Daley J, LazoKallanian S, Hatjiharissi E, Raab MS, et al. Protein kinase C inhibitor enzastaurin induces in vitro and in vivo antitumor activity in Waldenstrom macroglobulinemia. Blood. 2007; 109:4964-4972.

4. Podar K, Raab MS, Chauhan D, Anderson KC. The therapeutic role of targeting protein kinase $\mathrm{C}$ in solid and hematologic malignancies. Expert Opin Investig Drugs. 2007; 16:1693-1707.

5. Lee KW, Kim SG, Kim HP, Kwon E, You J, Choi HJ, Park JH, Kang BC, Im SA, Kim TY, Kim WH, Bang YJ. Enzastaurin, a protein kinase $\mathrm{C}$ beta inhibitor, suppresses signaling through the ribosomal S6 kinase and bad pathways and induces apoptosis in human gastric cancer cells. Cancer Res. 2008; 68:1916-1926.

6. Holler C, Piñón JD, Denk U, Heyder C, Hofbauer S, Greil R, Egle A. PKCbeta is essential for the development of chronic lymphocytic leukemia in the TCL1 transgenic mouse model: validation of PKCbeta as a therapeutic target in chronic lymphocytic leukemia. Blood. 2009; 113:2791-2794.

7. Zhang J, Sattler M, Tonon G, Grabher C, Lababidi S, Zimmerhackl A, Raab MS, Vallet S, Zhou Y, Cartron MA, Hideshima T, Tai YT, Chauhan D, et al. Targeting angiogenesis via a c-Myc/hypoxia-inducible factor-1alphadependent pathway in multiple myeloma. Cancer Res. 2009; 69:5082-5090.

8. Kuo WL, Liu J, Mauceri H, Vokes EE, Weichselbaum R, Rosner MR, Cohen EE. Efficacy of the multi-kinase inhibitor enzastaurin is dependent on cellular signaling context. Mol Cancer Ther. 2010; 9:2814-2824.

9. Shimokawa T, Seike M, Soeno C, Uesaka H, Miyanaga A, Mizutani H, Kitamura K, Minegishi Y, Noro R, Okano T, Yoshimura A, Gemma A. Enzastaurin has anti-tumour effects in lung cancers with overexpressed JAK pathway molecules. Br J Cancer. 2012; 106:867-875.

10. Kheirallah S, Fruchon S, Ysebaert L, Blanc A, Capilla F, Marrot A, Alsaati T, Frenois FX, Benhadji KA, Fournié JJ, Laurent G, Bezombes C. The serine-threonine kinase
p90RSK is a new target of enzastaurin in follicular lymphoma cells. Br J Pharmacol. 2013; 170:1374-1383.

11. Romano S, Nappo G, Calì G, Wang SY, Staibano S, D’Angelillo A, Ilardi G, Sorrentino A, Di Pace AL, Siano M, Bisogni R, Romano MF. Synergy between enzastaurin doxorubicin in inducing melanoma apoptosis. Pigment Cell Melanoma Res. 2013; 26:900-911.

12. Schönherr M, Bhattacharya A, Kottek T, Szymczak S, Köberle M, Wickenhauser C, Siebolts U, Saalbach A, Koczan D, Magin TM, Simon JC, Kunz M. Genomewide RNAi screen identifies protein kinase Cbeta and new members of mitogen-activated protein kinase pathway as regulators of melanoma cell growth and metastasis. Pigment Cell Melanoma Res. 2014; 27:418-430.

13. Vergote IB, Chekerov R, Amant F, Harter P, Casado A, Emerich J, Bauknecht T, Mansouri K, Myrand SP, Nguyen TS, Shi P, Sehouli J. Randomized, phase II, placebo-controlled, double-blind study with and without enzastaurin in combination with paclitaxel and carboplatin as first-line treatment followed by maintenance treatment in advanced ovarian cancer. J Clin Oncol. 2013; $31: 3127-3132$.

14. Carducci MA, Musib L, Kies MS, Pili R, Truong M, Brahmer JR, Cole P, Sullivan R, Riddle J, Schmidt J, Enas N, Sinha V, Thornton DE, et al. Phase I dose escalation and pharmacokinetic study of enzastaurin, an oral protein kinase $\mathrm{C}$ beta inhibitor, in patients with advanced cancer. J Clin Oncol. 2006; 24:4092-4099.

15. Chen YB, LaCasce AS. Enzastaurin. Expert Opin Investig Drugs. 2008; 17:939-944.

16. Oh Y, Herbst RS, Burris H, Cleverly A, Musib L, Lahn M, Bepler G. Enzastaurin, an oral serine/threonine kinase inhibitor, as second- or third-line therapy of non-small-cell lung cancer. J Clin Oncol. 2008; 26:1135-1141.

17. Wick W, Puduvalli VK, Chamberlain MC, van den Bent MJ, Carpentier AF, Cher LM, Mason W, Weller M, Hong S, Musib L, Liepa AM, Thornton DE, Fine HA. Phase III study of enzastaurin compared with lomustine in the treatment of recurrent intracranial glioblastoma. J Clin Oncol. 2010; 28:1168-1174.

18. Ghobrial IM, Moreau P, Harris B, Poon T, Jourdan E, Maisonneuve H, Benhadji KA, Hossain AM, Nguyen TS, Wooldridge JE, Leblond V. A multicenter phase II study of single-agent enzastaurin in previously treated Waldenstrom macroglobulinemia. Clin Cancer Res. 2012; 18:5043-5050.

19. Rampling R, Sanson M, Gorlia T, Lacombe D, Lai C, Gharib M, Taal W, Stoffregen C, Decker R, van den Bent MJ. A phase I study of LY317615 (enzastaurin) and temozolomide in patients with gliomas (EORTC trial 26054). Neuro Oncol. 2012; 14:344-350.

20. Gray JE, Altiok S, Alexandrow MG, Walsh FW, Chen J, Schell MJ, Tai DF, Bepler G. Phase 2 randomized study 
of enzastaurin (LY317615) for lung cancer prevention in former smokers. Cancer. 2013; 119:1023-1032.

21. Schwartzberg L, Hermann R, Flinn I, Flora D, Hsi ED, Hamid O, Shi P, Lin BK, Myrand SP, Nguyen TS, Dreyling $\approx$ M. Open-label, single-arm, phase II study of enzastaurin in patients with follicular lymphoma. Br J Haematol. 2014; 166:91-97.

22. Vergote I. Novel therapies, including enzastaurin, in the treatment of ovarian cancer. Expert Opin Investig Drugs. 2014; 23:579-598.

23. Ogbomo H, Biru T, Michaelis M, Loeschmann N, Doerr HW, Cinatl J Jr. The anti-tumoral drug enzastaurin inhibits natural killer cell cytotoxicity via activation of glycogen synthase kinase-3 $\beta$. Biochem Pharmacol. 2011; 81:251-258.

24. Gosiengfiao Y, Reichek J, Walterhouse D. What is new in rhabdomyosarcoma management in children? Paediatr Drugs. 2012; 14:389-400.

25. Kojima $\mathrm{Y}$, Hashimoto $\mathrm{K}$, Ando $\mathrm{M}$, Yonemori $\mathrm{K}$, Yamamoto H, Kodaira M, Yunokawa M, Shimizu C, Tamura K, Hosono A, Makimoto A, Fujiwara Y. Comparison of dose intensity of vincristine, d-actinomycin, and cyclophosphamide chemotherapy for child and adult rhabdomyosarcoma: a retrospective analysis. Cancer Chemother Pharmacol. 2012; 70:391-397.

26. Morgenstern DA, Baruchel S, Irwin MS. Current and future strategies for relapsed neuroblastoma: challenges on the road to precision therapy. J Pediatr Hematol Oncol. 2013; 35:337-347.

27. Park JR, Bagatell R, London WB, Maris JM, Cohn SL, Mattay KK. Children's Oncology Group's 2013 blueprint for research: neuroblastoma. Pediatr Blood Cancer. 2013; 60:985-993.

28. Raney B, Huh W, Hawkins D, Hayes-Jordan A, Million L, Rodeberg D, Teot L, Anderson J Soft Tissue Sarcoma Committee of the Children's Oncology Group, Arcadia, CA. Outcome of patients with localized orbital sarcoma who relapsed following treatment on Intergroup Rhabdomyosarcoma Study Group (IRSG) Protocols-III and -IV, 1984-1997: a report from the Children's Oncology Group. Pediatr Blood Cancer. 2013; 60:371-376.

29. Silverton L, Dean M, Moitra K. Variation and evolution of the $\mathrm{ABC}$ transporter genes $\mathrm{ABCB} 1, \mathrm{ABCC} 1$, ABCG2, ABCG5 and ABCG8: implication for pharmacogenetics and disease. Drug Metabol Drug Interact. 2011; 26:169-179.

30. Tamaki A, Ierano C, Szakacs G, Robey RW, Bates SE. The controversial role of ABC transporters in clinical oncology. Essays Biochem. 2011; 50:209-232.

31. Ieiri I. Functional significance of genetic polymorphisms in P-glycoprotein (MDR1, ABCB1) and breast cancer resistance protein (BCRP, ABCG2). Drug Metab Pharmacokinet. 2012; 27:85-105.

32. Levine AJ, Oren $M$. The first 30 years of $\mathrm{p} 53$ : growing ever more complex. Nat Rev Cancer. 2009; 9:749-758.
33. Chen L, Tweddle DA. p53, SKP2, and DKK3 as MYCN Target Genes and Their Potential Therapeutic Significance. Front Oncol. 2012; 2:173.

34. O'Brian CA, Ward NE, Stewart JR, Chu F. Prospects for targeting protein kinase $\mathrm{C}$ isozymes in the therapy of drugresistant cancer - an evolving story. Cancer Metastasis Rev. 2001; 20:95-100.

35. Zhan M, Yu D, Liu J, Glazer RI, Hannay J, Pollock RE. Transcriptional repression of protein kinase Calpha via Sp1 by wild type p53 is involved in inhibition of multidrug resistance 1 P-glycoprotein phosphorylation. J Biol Chem. $2005 ; 280: 4825-4833$.

36. Aller SG, Yu J, Ward A, Weng Y, Chittaboina S, Zhuo R, Harrell PM, Trinh YT, Zhang Q, Urbatsch IL, Chang G. Structure of P-glycoprotein Reveals a Molecular Basis for Poly-Specific Drug Binding. Science. 2009; 323:1718-1722.

37. Hanania N, Lezenes JR, Castagna M. Tumorigenicityassociated expression of protein kinase $\mathrm{C}$ isoforms in rhabdomyosarcoma-derived cells. FEBS Lett. 1992; 303:15-18.

38. Bouché M, Zappelli F, Polimeni M, Adamo S, Wetsel WC, Senni MI, Molinaro M. Rapid activation and down-regulation of protein kinase $\mathrm{C}$ alpha in 12-O-Tetradecanoylphorbol-13-acetate-induced differentiation of human rhabdomyosarcoma cells. Cell Growth Differ. 1995; 6:845-852.

39. Kim YS, Jin SH, Lee YH, Park JD, Kim SI. Differential expression of protein kinase $\mathrm{C}$ subtypes during ginsenoside Rh2-lnduced apoptosis in SK-N-BE(2) and C6Bu-1 cells. Arch Pharm Res. 2000; 23:518-524.

40. Svensson K, Zeidman R, Trollér U, Schultz A, Larsson C. Protein kinase $\mathrm{C}$ betal is implicated in the regulation of neuroblastoma cell growth and proliferation. Cell Growth Differ. 2000; 11:641-648.

41. Lange L, Keppner-Witter S, Grigat J, Spänkuch B. Combinatorial inhibition of Plk1 and PKC $\beta$ in cancer cells with different p53 status. Oncotarget. 2014; 5:2263-2275.

42. Mukohara T, Nagai S, Koshiji M, Yoshizawa K, Minami H. Phase I dose escalation and pharmacokinetic study of oral enzastaurin (LY317615) in advanced solid tumors. Cancer Sci. 2010; 101:2193-2199.

43. Budworth J, Davies R, Malkhandi J, Gant TW, Ferry DR, Gescher A. Comparison of staurosporine and four analogues: their effects on growth, rhodamine 123 retention and binding to P-glycoprotein in multidrug-resistant MCF-7/Adr cells. Br J Cancer. 1996; 73:1063-1068.

44. Sterz K, Möllmann L, Jacobs A, Baumert D, Wiese M. Activators of P-glycoprotein: Structure-activity relationships and investigation of their mode of action. ChemMedChem. 2009; 4:1897-1911.

45. Häcker HG, de la Haye A, Sterz K, Schnakenburg G, Wiese M, Gütschow M. Analogs of a 4-aminothieno[2,3-d]pyrimidine lead (QB13) as modulators of P-glycoprotein substrate specificity. Bioorg Med Chem Lett. 2009; 19:6102-6105. 
46. Serova M, Astorgues-Xerri L, Bieche I, Albert S, Vidaud M, Benhadji KA, Emami S, Vidaud D, Hammel P, Theou-Anton N, Gespach C, Faivre S, Raymond E. Epithelial-to-mesenchymal transition and oncogenic Ras expression in resistance to the protein kinase Cbeta inhibitor enzastaurin in colon cancer cells. Mol Cancer Ther. 2010; 9:1308-1317.

47. Germann UA, Chambers TC, Ambudkar SV, Licht T, Cardarelli CO, Pastan I, Gottesman MM. Characterization of phosphorylation-defective mutants of human P-glycoprotein expressed in mammalian cells. J Biol Chem. 1996; 271:1708-1716.

48. Goodfellow HR, Sardini A, Ruetz S, Callaghan R, Gros P, McNaughton PA, Higgins CF. Protein kinase C-mediated phosphorylation does not regulate drug transport by the human multidrug resistance P-glycoprotein. J Biol Chem. 1996; 271:13668-13674.

49. Rigor RR, Hawkins BT, Miller DS. Activation of PKC isoform beta(I) at the blood-brain barrier rapidly decreases P-glycoprotein activity and enhances drug delivery to the brain. J Cereb Blood Flow Metab. 2010; 30:1373-1383.

50. Wang X, Hawkins BT, Miller DS. Activating PKC- $\beta 1$ at the blood-brain barrier reverses induction of P-glycoprotein activity by dioxin and restores drug delivery to the CNS. J Cereb Blood Flow Metab. 2011; 31:1371-1375.

51. Dolghih E, Bryant C, Renslo AR, Jacobson MP. Predicting binding to p-glycoprotein by flexible receptor docking. PLoS Comput Biol. 2011; 7:1002083.

52. Ferreira RJ, Ferreira MJU, dos Santos DJ. Molecular docking characterizes substrate-binding sites and efflux modulation mechanisms within P-glycoprotein. J Chem Inf Model. 2013; 53:1747-1760.

53. Tan W, Mei H, Chao L, Liu T, Pan X, Shu M, Yang L. Combined QSAR and molecule docking studies on predicting P-glycoprotein inhibitors. J Comput Aided Mol Des. 2013; 27:1067-1073.

54. Ghafourian T Identification of substrates of P-Glycoprotein using in-silico methods Kent Academic Repository 2013 (http://kar.kent.ac.uk/id/eprint/42855).

55. Osho V, Ojo O, Ghafourian T. Evaluation of QSAR and ligand enzyme docking for the identification of ABCB1 substrates. Kent Academic Repository 2013 (http://kar.kent. ac.uk/id/eprint/42820).

56. Masanek U, Stammler G, Volm M. Modulation of multidrug resistance in human ovarian cancer cell lines by inhibition of P-glycoprotein 170 and PKC isoenzymes with antisense oligonucleotides. J Exp Ther Oncol. 2002; 2:37-41.

57. Haber M, Smith J, Bordow SB, Flemming C, Cohn SL, London WB, Marshall GM, Norris MD. Association of high-level MRP1 expression with poor clinical outcome in a large prospective study of primary neuroblastoma. J Clin Oncol. 2006; 24:1546-1553.

58. Dreicer R, Garcia J, Hussain M, Rini B, Vogelzang N, Srinivas S, Somer B, Zhao YD, Kania M, Raghavan D.
Oral enzastaurin in prostate cancer: a two-cohort phase II trial in patients with PSA progression in the non-metastatic castrate state and following docetaxel-based chemotherapy for castrate metastatic disease. Invest New Drugs. 2011; 29:1441-1448.

59. Lainey E, Sébert M, Thépot S, Scoazec M, Bouteloup C, Leroy C, De Botton S, Galluzzi L, Fenaux P, Kroemer G. Erlotinib antagonizes $\mathrm{ABC}$ transporters in acute myeloid leukemia. Cell Cycle. 2012; 11:4079-4092.

60. Vergote I, Amant F, Oskay-Oezcelik G, Musib L, Michel AL, Darstein C, Kania M, Bauknecht T, Sehouli J. Carboplatin and paclitaxel in combination with oral enzastaurin in advanced ovarian or primary peritoneal cancer: results from a safety lead-in study. Int J Gynecol Cancer. 2009; 19:1505-1510.

61. Kotchetkov R, Cinatl J, Blaheta R, Vogel JU, Karaskova J, Squire J, Hernáiz Driever P, Klingebiel T, Cinatl J Jr. Development of resistance to vincristine and doxorubicin in neuroblastoma alters malignant properties and induces additional karyotype changes: a preclinical model. Int $\mathrm{J}$ Cancer. 2003; 104:36-43.

62. Kotchetkov R, Driever PH, Cinatl J, Michaelis M, Karaskova J, Blaheta R, Squire JA, Von Deimling A, Moog J, Cinatl J Jr. Increased malignant behavior in neuroblastoma cells with acquired multi-drug resistance does not depend on P-gp expression. Int J Oncol. 2005; 27:1029-1037.

63. Cinatl J Jr, Cinatl J, Radsak K, Rabenau H, Weber B, Novak M, Benda R, Kornhuber B, Doerr HW. Replication of human cytomegalovirus in a rhabdomyosarcoma cell line depends on the state of differentiation of the cells. Arch Virol. 1994; 138:391-401.

64. Michaelis M, Rothweiler F, Klassert D, von Deimling A, Weber K, Fehse B, Kammerer B, Doerr HW, Cinatl J Jr. Reversal of P-glycoprotein-mediated multidrug resistance by the murine double minute 2 antagonist nutlin-3. Cancer Res. 2009; 69:416-421.

65. Weber K, Bartsch U, Stocking C, Fehse B. A multicolor panel of novel lentiviral "gene ontology" (LeGO) vectors for functional gene analysis. Mol Ther. 2008; 16:698-706.

66. Rothweiler F, Michaelis M, Brauer P, Otte J, Weber K, Fehse B, Doerr HW, Wiese M, Kreuter J, Al-Abed Y, Nicoletti F, Cinatl J Jr. Anticancer effects of the nitric oxide-modified saquinavir derivative saquinavir-NO against multidrug-resistant cancer cells. Neoplasia. 2010; 12:1023-1030.

67. Michaelis M, Rothweiler F, Nerreter T, Sharifi M, Ghafourian T, Cinatl J Jr. Karanjin interferes with ABCB1, ABCC1, and ABCG2. J Pharm Pharm Sci. 2014; 17:92-105.

68. Michaelis M, Rothweiler F, Nerreter T, Van Rikxoort M, Sharifi M, Wiese M, Ghafourian T, Cinatl J Jr. Differential effects of the oncogenic BRAF inhibitor PLX4032 
(vemurafenib) and its progenitor PLX4720 on ABCB1 function. J Pharm Pharm Sci. 2014; 17:154-168.

69. Allen JD, van Loevezijn A, Lakhai JM, van der Valk M, van Tellingen O, Reid G, Schellens JH, Koomen GJ, Schinkel AH. Potent and specific inhibition of the breast cancer resistance protein multidrug transporter in vitro and in mouse intestine by a novel analogue of fumitremorgin $\mathrm{C}$. Mol Cancer Ther. 2002; 1:417-425.
70. Chen IJ, Foloppe N. Tackling the conformational sampling of larger flexible compounds and macrocycles in pharmacology and drug discovery. Bioorg Med Chem. 2013; 21:7898-7920.

71. Bikadi Z, Hazai I, Malik D, Jemnitz K, Veres Z, Hari P, Ni Z, Loo TW, Clarke DM, Hazai E, Mao Q. Predicting P-glycoprotein-mediated drug transport based on support vector machine and three-dimensional crystal structure of P-glycoprotein. PLoS One. 2011; 6:e25815. 